\title{
Organizational culture of Czech manufacturing companies: An empirical typology*
}

Růžena Lukášová, Emilie Franková, Alois. Surynek**

The contribution presents the results of research into organizational culture of Czech manufacturing companies. The study was carried out on a sample of respondents from top, medium and low management from 74 companies. The analysis of organizational culture was performed on the levels of values, norms and selected aspects of perceiving and behaving which are shared in the organization. The data obtained through questionnaires were processed by means of factor and cluster analyses. The research has resulted in an empirical typology presenting the typical contents of organizational culture of Czech manufacturing companies.

Der Beitrag präsentiert Forschungsergebnisse über Organisationskultur in tschechischen Produktionsbetrieben. Die Studie wurde unter Vertretern der höheren, mittleren und niederen Managementebenen aus 74 Unternehmen durchgeführt. Die Analyse der Organisationskultur konzentrierte sich auf Werte, Normen und ausgewählte Aspekte von Wahrnehmung und Verhalten, die in einer Organisation geteilt werden. Die durch Frageboegen gewonnenen Daten wurden mittels Faktor- und Cluster-Analysen ausgewertet. Im Ergebnis wurde eine emirische Typologie abgeleitet, welche die typischen Inhalte der Organisationskultur in tschechischen Produktionsbetrieben widerspiegelt.

Key words: Organizational culture, Empirical typology, Czech manufacturing companies

** Manuscript received:23.05.05, acceptet:10.08.06 (1 revision)

** Růžena Lukášová, Doc./PhDr/Csc., Masaryk University, Faculty of Economics and Administration, Department of Public Economics. Main research areas: Organizational behaviour, organizational culture, organizational image. Corresponding address: lukasova@econ.muni.cz

Emilie Franková, PhDr./PhD., Brno University of Technology, Faculty of Business and Management. Main research areas: Organizational behaviour, organizational culture, organizational culture supporting creativity and innovations. Corresponding address: frankova@fbm.vutbr.cz

Alois Surynek, PhDr., University of Economics Prague, Faculty of Business Administration. Main research areas: Organizational behaviour, organizational culture. Corresponding address: surynet@vse.cz 


\section{Introduction}

Organizational culture is a phenomenon which is very complex and complicated, yet it has a significant influence on the performance of an organization. Various authors agree that organizational culture significantly affects the operation and effectiveness of organizations (Denison 1990; Kotter/Heskett 1992; Marcoulides/Heck 1993; Wiley/Brooks 2000) and represents an important determining factor for the quality of the lives of the organization's members (O’Reilly III et al. 1991).

Although there is no agreement on a single definition of organizational culture, it may be generally stated that the concept of organisational culture tends to be defined as a set of basic assumptions, values, attitudes and norms of behaviour shared within an organization and manifested through their members' perceptions, thoughts, feelings and behaviour, as well as artefacts of both material and non-material nature (Denison 1990; Drennan 1992; Schein 1992; Trice/Beyer 1992; Martin 1992; Brown 1995; Sackmann 2002; Lukášová/Nový et al. 2004). As a set of assumptions, beliefs, values and norms of behaviour, organizational culture affects the internal operation and efficiency of organizations. As a manner of perceiving and thinking, however, it also affects the organization's external behaviour towards the environment. The knowledge of the content of organizational culture (i.e. what assumptions, values, attitudes, norms of behaviour, etc. are shared within the organization) thus provides its management with important information: it is then able to predict the tendencies in which organizations behave and to assess to what an extent the content of culture encourages efficiency, strategy implementation or the organization's accommodation to its environment.

The identification of organizational culture and the understanding of its content, however, is a complex issue. A suitable scientific tool which is relatively frequently used for the analysis and identification of such complex contents of the social reality as organizational culture consists of the construction of typologies. The purpose of constructing typologies (both theoretical and empirical) is to classify, sort out and clarify the complex content of the social reality and to find the typical constellations of selected characteristics of a researched phenomenon. The typologies of organizational culture revealed in this way are significant because the identification of the typical contents of organizational culture (which may change according to the development of the environment) contributes new findings to the field. Moreover, typologies also have a highly practical importance because the types of culture representing the typical constellations of selected characteristics of a researched phenomenon enable managers to compare the contents of their organization's culture with typical cases of actually existing cultures. Such a comparison can thus throw more light on their own culture. 
A number of typologies of organizational culture have been published in Western Europe over the past 20 years (Deal/Kennedy 1982; Handy 1993; Trompenaars 1993; Hall 1995; Goffee/Jones 1998; Cameron/Quinn 1999; Fernandez/Hogan 2003 etc.). These studies identify the typical contents of culture from various perspectives, relating it to various aspects of the organization itself or its external environment. However, as organizational culture is, among others, determined by the environment in which an organization exists, the question arises of whether the typologies developed and identified in Western European countries also describe the typical contents of cultures of organizations from the countries of the former Eastern bloc, including the Czech Republic. This issue becomes particularly acute in connection with those aspects of the content of organizational culture which relate to an organization's behaviour towards the environment. The necessity of analysing organizational culture from this point of view is, in the case of Czech companies, heightened by the fact that many of them do not yet have any explicitly formulated strategies. The prevailing values, attitudes and norms of behaviour thus interact with the environment and implicitly determine the behaviour of such companies in the market.

\section{Aims of research}

The aim of the study which gave rise to the findings presented in this article was to use the empirical construction of typology to delimit the typical contents of strategic aspects of organizational culture of Czech manufacturing companies. ${ }^{1}$

\section{Methods used}

Most researchers define organizational culture as a complex and multi-level phenomenon with some indicators clearly visible to external observers (artefacts, behaviour), others less observable (values and norms of behaviour) and still others entirely hidden and hard to uncover (basic assumptions). When diagnosing organizational culture, it is therefore considered desirable to describe organizational culture on several levels (Schein 1985; Sackmann 1991).

The core of organizational culture in relation to companies' strategic behaviour and effectiveness is considered to consist primarily of organizational values (cf. e.g. Cameron/Quinn 1999). Such values express the general preferences which enter into the decision-making and behaving of people in organizations. An important indicator is, however, also constituted by norms of behaviour which

1 The article was written using data obtained in a grant project No. 402/02/0114 "Organizational Culture of Czech Companies" of the Grant Agency of the Czech Republic. At the same time, it is an input study of the research project MSM 6138439905 "New Theory of Economics and Management". 
govern the unwritten rules for behaviour applied and accepted in organizations. It is these rules which affect the everyday behaviour of employees in the organization, thereby determining not only the internal effectiveness but also behaviour towards the exterior, i.e. one's partners and customers. The values and norms determining perceiving, thinking and behaviour are elements of the internal level of organizational culture. The external (visible) level consists of the employees' behaviour. As a result, the following indicators of organizational culture have been selected for research: 1. organizational values, 2. norms of behaviour in the organization, 3. selected aspects of employees' perceiving and behaviour.

Because the study could not follow up any relevant empirical findings about the values, norms of behaviour and ways of perceiving and behaving present in Czech manufacturing companies, it was necessary to start with a qualitative preliminary study. This was meant to acquire, by means of the method of incomplete sentences, the information necessary for the selection of questionnaire items.

The questionnaire which was used in the preliminary study in order to identify values and norms of behaviour present in Czech companies consisted of 73 sentence introductions with verbs meant to provoke the respondents' relevant answers. The respondents' task was to reflect on what is considered as important within their companies (i.e. to what significance is ascribed) and complete the submitted verbal phrases (e.g. it is considered important in the company to manifest..., not to show..., to be... ), thereby creating meaningful sentences about the culture of their companies. Care was to taken to emphasise that the respondents should provide answers from the perspective of external observers present in their companies (not to express their personal preferences or beliefs about what answers might be expected). However, respondents were not asked to complete all sentences; the verbal phrases were only meant to stimulate their thinking about their organization's culture and encourage them to provide answers relevant for the determination of values and norms held in the company. The questionnaire was also supplemented with another brief method of incomplete sentences to identify the norms of behaviour present in the company in selected situations.

On the levels of perceiving and behaving, the choice of indicators of organizational culture was based on Cameron and Quinn (1999), who identified the following six dimensions with a provable effect on an organization's effectiveness:

1. Dominant characteristics (characteristic features of the environment and the atmosphere within the organization);

2. Organizational leadership (what is considered to be leadership within an organization, what are considered to be leadership abilities); 
3. Management of employees (what is characteristic for managerial style, what methods of management are used);

4. Organization glue (what holds the organization together);

5. Strategic emphases (what is emphasized within the organization, what the company is aimed at);

6. Criteria of success (how success is defined in the organization).

As Cameron and Quinn's dimensions concern beliefs, opinions and corresponding ways of behaviour mainly oriented internally towards the organization, the selected indicators were supplemented with several other indicators concerning the perception of the environment, the competition and one's company in relation to the environment. Incomplete sentences were formulated for each area under investigation and submitted to respondents for completion.

The qualitative preliminary research was carried out on a sample of 85 managers with each manager representing a different company. The answers provided were sorted out and frequencies of occurrence calculated for each area under investigation. Those categories of answers which had contents relevant for the given issue and which were relatively frequent, were used as items in the final version of the research questionnaires.

The results of the qualitative preliminary research were used to construct three research questionnaires with the working titles of: Organizational values questionnaire, Behavioural norms questionnaire and Organizational behaviour questionnaire.

Organisational values questionnaire, used in the actual research, contained 85 organizational values formulated as brief statements. Respondents used the fivepoint Likert scale to evaluate the extent to which the ways of thinking and behaving described in the questionnaire are considered as important in their company, i.e. how they are emphasised and, unofficially, held as important.

Behavioural norms questionnaire contained 56 items expressing the norms of behaviour expressed in the form of brief statements. Respondents used the fivepoint Likert scale to evaluate the extent to which they agree whether the norms of behaviour stated in the questionnaire are accepted in the company (i.e. are unofficially and unconsciously acknowledged and reflected in employee's behaviour).

Organizational behaviour questionnaire was aimed to cover 10 content areas meant to identify the content of organizational culture on the levels of perceiving and behaving implicitly determined by basic assumptions, beliefs and values shared in the company. Each particular area under investigation was characterized by the beginning of a brief statement concluded by several possible answers formulated on the basis of the preliminary study. Respondents 
used the five-point scale to assess the extent to which each possible answer is typical of the company's behaviour. The final questionnaire included the following questions (or the beginnings of brief statements):

1. Our company is a place characterized by ...;

2. The company is mainly oriented towards ...;

3. Activities and attention within the company are mainly oriented towards...;

4. The source of company cohesion is...;

5. Managing people in the company means mainly...;

6. Managers expect their subordinates mainly to...;

7. The company's success is assessed by the management mainly according to...;

8. The environment in which the company operates is perceived by the management as...;

9. The company perceives competition as...;

10.In relation to the market and environment, the company is....

Questions which refer to similar content areas were arranged in such a way as to prevent that they would follow each other.

\section{Research sample}

The sample consisted of 74 manufacturing companies from various branches of industry. The composition of the sample as regards the size and the field of business is provided in Table 1.

As the aim was to identify the contents of organizational culture of Czech companies with respect to their "strategic" behaviour, respondents were drawn from the ranks of top, middle and low management (whose thinking, perceiving and behaving is crucial for the strategic behaviour of their companies). The numbers of respondents were different for different companies depending on their size. The total number of respondents was 467 , out of which there were 348 men and 105 women (14 persons failed to provide a specification of their sex). This included 182 members of top management, 156 members of middle management and 112 members of low management (17 persons failed to provide a specification of their rank). The research was carried out from June to November 2004. 


\section{Manner of data processing}

The data obtained in the Organizational values questionnaire, Behavioural norms questionnaire and Organizational behaviour questionnaire were processed by means of factor analysis. This identified the content components of organizational culture of Czech manufacturing companies on the levels of organizational values, norms of behaviour and ways of perceiving and behaving present in the organizations. For each extracted factor and each respondent, a factor score was calculated. Factor scores were then used for a cluster analysis (for data obtained by means of all three methods). In this way, an empirical typology of organizational culture of Czech manufacturing companies was obtained and identified on the selected levels of analysis.

Table 1. The composition of the research sample of companies as regards their size and field of business:

\begin{tabular}{|l|c|c|c|c|}
\hline \multirow{2}{*}{\multicolumn{1}{|c|}{ Industry branch }} & \multirow{2}{*}{$\begin{array}{c}\text { Number of } \\
\text { companies } \\
\text { involved }\end{array}$} & \multicolumn{3}{c|}{ Number of employees } \\
\cline { 3 - 5 } & 7 & $\mathbf{0 - 4 9}$ & $\mathbf{5 0 - 2 4 9}$ & over 250 \\
\hline Food processing and tobacco & 1 & 0 & 1 & 0 \\
\hline Textile and clothing & 3 & 2 & 1 & 0 \\
\hline Wood-working & 1 & 1 & 0 & 0 \\
\hline Paper mills and polygraphy & 2 & 1 & 1 & 0 \\
\hline Chemical and pharmaceutical & 8 & 2 & 4 & 2 \\
\hline Rubber-making and plastics & 2 & 0 & 1 & 1 \\
\hline $\begin{array}{l}\text { Glass, ceramics, china and } \\
\text { construction materials }\end{array}$ & 12 & 4 & 4 & 4 \\
\hline Metal and metalworking & 14 & 5 & 5 & 4 \\
\hline $\begin{array}{l}\text { Manufacture of machinery and } \\
\text { equipment for production }\end{array}$ & 11 & 5 & 4 & 2 \\
\hline $\begin{array}{l}\text { Manufacture of electrical and optic } \\
\text { instruments }\end{array}$ & & & & 0 \\
\hline $\begin{array}{l}\text { Manufacture of transportation } \\
\text { vehicles }\end{array}$ & 2 & 1 & 1 & 0 \\
\hline Other processing industries & 5 & 2 & 3 & 0 \\
\hline Agriculture & 2 & 0 & 2 & 0 \\
\hline Fishing and fish farming & 1 & 1 & 0 & 1 \\
\hline $\begin{array}{l}\text { Manufacture and distribution of } \\
\text { electricity, natural gas and water }\end{array}$ & 1 & 0 & 0 & 0 \\
\hline Construction & 2 & 2 & 0 & $\mathbf{3 4}$ \\
\hline $\mathbf{\Sigma}$ & $\mathbf{7 4}$ & $\mathbf{3 0}$ & $\mathbf{3 0}$ & \\
\hline
\end{tabular}

\section{Results}

\section{Content components of organizational culture of Czech manufacturing companies on the level of organizational values}

Through factor analysis of data obtained in the Organizational values questionnaire, five relatively consistent factors were extracted. As the questionnaire included 85 values and the tables with items included in particular factors are very extensive, only a brief description of the factors identified is 
provided here (Lukášová 2006). The description was formulated on the basis of categorizating those items which are comprised in particular factors with a loading exceeding 0.400 .

Factor 1, as revealed by the process of sorting and categorization, is primarily made up of values oriented towards:

1. Friendly atmosphere, good relations, cooperation, information sharing;

2. Respect for employees, support of employees, development of employees;

3. Encouragement of participation;

4. Encouragement of innovativeness and employees' creativity.

As the content of the factor indicates, the support of innovativeness, creativity and experimenting in Czech manufacturing companies is connected with orientation towards employees - with affording them respect and allowing them to develop and assert themselves. In harmony with its content, this factor has been called orientation to employees and atmosphere in the company.

Factor 2, which has a highly consistent content, is primarily made up of values oriented towards:

1. High quality of products and services;

2. Perfection, precision, keeping of deadlines;

3. Honesty towards customers, accommodation to customers' needs, achieving customer satisfaction.

As a result of the clear orientation towards quality (in the sense of both good quality products and achieving customer satisfaction), this factor has been called orientation to quality and customer satisfaction.

Factor 3 has a characteristic orientation towards:

1. Expansion in the market and defeat of the competition;

2. Flexible reactions to new opportunities;

3. Seeking out new opportunities and possible directions for the company's development.

The values contained in this factor are linked with flexibility, dynamism, and activity bordering on marketing aggressiveness. As a result, it has come to be called orientation to expansion.

Factor 4 is a counterpart to Factor 3. It has been called orientation to external image and certainty, because it is made up of items which emphasise the following:

1. Upport of the region (city, health services, sport, culture), construction of a positive external image; 
2. Respect for traditions;

3. Observance of laws and regulations, protection of the environment;

4. Careful progress, thoughtful investments, use of tried methods;

5. Security for employees.

Although these items may appear diverse at first sight, they all include orientation to various kinds of security.

Items making up Factor 5 express the company's value orientation towards:

1. Low costs, seeking out savings;

2. Internal efficiency;

3. Economic results, profit.

As a result, this factor has been called orientation to efficiency and low costs.

\section{Content components of organizational culture of Czech manufacturing companies on the level of norms of behaviour}

The data obtained through the Behavioural norms questionnaire was subjected to factor analysis and 4 factors were calculated. The following description of the contents of the particular factors (Lukášová 2006) includes factors identified on the basis of those items which load on a given factor with a loading exceeding 0.400 .

The categorization of the norms of behaviour constituting Factor $6^{2}$ revealed that the major categories of norms are:

1. Responsibility towards the company;

2. Company loyalty;

3. Involvement and engagement for the company's benefit;

4. Independence, flexibility, "open mind";

5. Professionalism, self-development.

The culture characterized by the above-mentioned categories of norms has been therefore called a culture of involvement and responsibility.

2 Although factor analysis was carried out independently for the data obtained through the Organizational values questionnaire, Behavioural norms questionnaire and Organizational behaviour questionnaire, the factors have been numbered consecutively in order to facilitate the interpretation of the results of the cluster analysis (see below), which was carried out uniformly for all identified factors together. 
The norms of behaviour present in Factor 7 have to do mainly with moral aspects of behaviour. The factor includes, above all, the following categories of norms:

1. Politeness and honesty towards fellow employees and customers;

2. Openness towards fellow employees;

3. Helpfulness and cooperation towards fellow employees.

In addition to the above-mentioned categories, the factor is also constituted by those items (though loading on it with lower loadings) which are connected to professionalism, self-education, self-development, and employees' activity and initiative. It is thus clear that the norms of behaviour related to politeness and honesty are connected, in the minds of respondents, with professionalism. With view to the strongest items present in this factor, this type of culture has been called a culture of ethic and friendship.

Factor 8 is characterized by a relatively negative content of norms of behaviour present in Czech manufacturing companies. It has been called a culture of passivity and conformity. The main categories of behaviour which constitute this factor include:

1. Satisfaction with the status quo, non-involvement;

2. Conformity, obeying orders, accommodation to majority opinions;

3. Insincerity, caution about one's own statements.

Factor 9 is a counterpart to Factor 8 . The contents of the norms which constitute this factor may be expressed as:

1. Competitiveness, careerism;

2. Fight for positions and money.

The type of culture characterized by the above-mentioned features has thus been called a culture of competitiveness and avidity.

\section{Content components of organizational culture of Czech manufacturing companies on the level of perceiving and behaving}

The factor analysis of data obtained by means of the Organizational behaviour questionnaire was calculated for 5 factors. As in the case of the previous two questionnaires, the descriptions of the particular factors are based on those items which load on a given factor with a loadings exceeding 0.400 (Lukášová 2005).

Factor 10 is constituted primarily by those questionnaire items which concern orientation to employees and atmosphere in the company. Such an orientation is manifested in the organization's behaviour mainly in the manner in which people are managed (managing people in the company means giving them freedom and independence, enabling them to come up with creative 
solutions, motivating them, enabling them to participate, creating conditions for their work). The behaviour which is encouraged is also expected (i.e. creativity, ideas, improvement, individual responsibility, etc.). The orientation to employees is linked in the organization's behaviour with the preparation of a friendly environment, positive atmosphere, encouragement of cooperation rather than an assertion of power. Most employees know how they contribute towards meeting the strategy. The shared goals, belief in success, desire to achieve something and willingness to create something new contribute to the cohesion of the company. Criteria of success are connected with people - both inside the company (employees' satisfaction) and ouside the company (customers' satisfaction). An additional criterion of success is quality of production which is a precondition for customers' satisfaction.

Factor 11, called orientation to market and customers, is constituted mainly by those items which are related to the company's behaviour in the market. With respect to the external environment, the company is flexible, active, open and perceptive. The company's activities are aimed towards obtaining / strengthening a strong position in the market and defeating the competition. This is, on the one hand, connected with focusing its activities on customer satisfaction and quality of service, and with willingness to risk on the other. While Factor 10 is more concerned with the internal orientation of the organization, Factor 11 is oriented towards the exterior - the environment and the market.

Factor 12 is rather specific in comparison with the other factors because is it independently constituted by the manner of perceiving the environment, typical of the organization. The items which load on it with a positive polarity express the perception of the environment as stable, friendly, positive and knowable, while those items which load on it with a negative polarity express that the environment is not perceived as a threat, or as complicated, demanding and hostile. The perception of the environment as stable is connected with the feeling that the company is not under pressure from the competition and there is no sense of danger and fear of termination; the competition is not perceived as a serious obstacle.

Factor 13 combines items which emphasise orientation to performance and defeat of competition. The focus of the company is on defeating its competition and acquiring a larger market share. Competition is seen as an rival who has to be defeated if one is to achieve supremacy in the market. Managers expect their subordinates to be mainly orienated to performance and results.

Factor 14 is, by contrast, constituted by items which express the company's orientation to survival. The company is oriented towards overcoming difficulties, safeguarding its competiveness, being able to ensure production, increasing productivity and keeping its customers. The orientation to survival is connected with directive management inside the company - managing 
employees means mainly organizing their work, assigning tasks to them and overseeing how tasks are fulfilled. Employees are then expected to follow the orders and instructions in a disciplined manner. The management assesses the company's success according to external achievements - audits and certifications obtained.

\section{Empirical types of organizational culture of Czech manufacturing companies identified on the levels of values, norms and selected aspects of perceiving and behaviour}

After describing the content components of organizational cultures of Czech manufacturing companies identified on the levels of values, norms, perceiving and behaviour in organizations, attention will be paid to the results of cluster analysis in order to identify the empirical types of organizational cultures of Czech manufacturing companies. Cluster analysis was based on factor scores calculated for every factor and every individual respondent. The analysis was carried out by means of the 'quick clusters' method for two, three, four and five clusters. As the most reasonable (i.e. neither too general nor too specific) solution was chosen the solution for four clusters. The results of cluster analysis for four clusters are provided in Graph.

Cluster 1 is, as Graph 1 shows, characterized primarily by a high level of Factor 4 on the level of values (orientation to external image and certainty) and Factor 8 on the level of norms of behaviour (culture of passivity and conformity). This means that companies with this type of culture consider it important to proceed cautiously, use tried methods, respect traditions, observe laws and regulations and ensure security in all respects (for employees, for the organization, for the region). This is linked with the emphasis they place on creating a positive external image by means of supporting health care, sports, culture, etc. The prevailing norms of behaviour are characterized mainly by satisfaction with the status quo, conformity, submission to instructions and accommodation to majority opinions. By contrast, this type of culture exhibits a relatively low level of Factor 6 (culture of involvement and responsibility), which is evidence of the absence of the importance of norms of behaviour encouraging responsibility towards the company, involvement and engagement for the company's benefit, independence, flexibility, and increase of employees' professionalism and self-development. The values and norms prevalent in companies with this culture seem to be linked, on the level of behaviour, with indistinct 'strategic' orientation (Factors 10, 12, 13, and 14 are on a relatively low level). What is, however, typical for this type of culture is its lack of orientation to the market and search for new opportunities in the market.

This is indicated by the very low level of Factor 11 on the level of behaviour (orientation to the market and customers) and Factor 3 on the level of values (orientation to expansion). The company therefore does not consider it important 
to look for new directions and possibilities of development, to react flexibly to new opportunities and to expand in the market. On the level of behaviour, this is connected with the fact that the company's activities are only marginally oriented to meeting customers' needs and providing high quality service. The company's behaviour is passive and inflexible. Its employees are not willing to risk, they do not strive to defeat the competitors and the company appears 'closed' towards the external environment.

The interpretation of the content of Cluster $\mathbf{2}$ is very difficult because, as Graph 2 indicates, it is characterized by a relatively high and comparatively balanced levels of all factors. The overall content of this cluster is therefore more or less positive - there is a prevalence of norms of behaviour expressing employees' involvement and responsibility on the one hand, and, on the other, a preponderance of ethical and friendly norms over norms typical for both the culture of passivity and conformity and the culture of competitiveness and avidity. High levels are manifested by factors stressing the importance of employees (Factor 1 on the level of values and Factor 10 on the level of the organization's behaviour). The better-than-average levels of all factors also indicate a certain 'strategic' ambivalence and internal incongruity present on the level of values (i.e. whatever is considered as important in the company) and the level of behaving and perceiving in the company.

There may be several reasons for this result. First, the respondents may not have followed the instructions asking them to use the entire scale - they may have set too high a level on the scales or given insufficient thought to the items of the questionnaire, etc. This, however, is unlikely to have happened on such a large scale owing to the presence of qualified questionners cautioning the respondents to follow the instructions. The second possible explanation may be that the cluster characterizes a culture with a vague content and a strategic ambivalence for which most values appear as important. In other words, these companies hold values with contrary contents and implement incongruent activities and the respondents have not perceived this discrepancy on the selected levels, i.e. the levels of values and behaviour. With view to the fact that the discrepancy of the contents of organizational culture of some Czech manufacturing companies on the level of values has been identified in some other studies of organizational culture of Czech companies, too (Lukášová 2004), the second explanation seems to be more likely. 
Figure 1. Results of cluster analysis

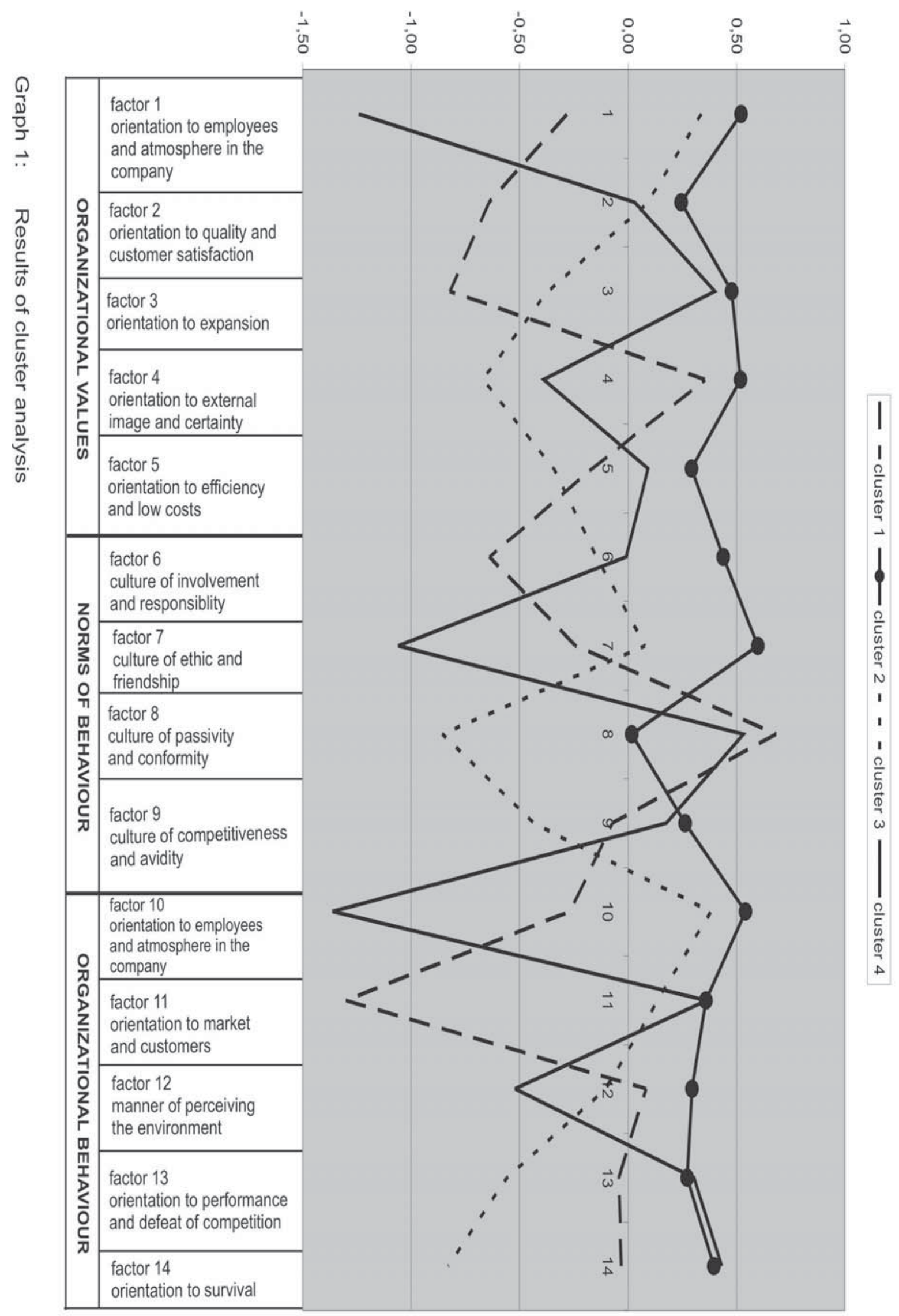


Cluster 3 characterizes a culture significantly oriented towards employees the harmony of this orientation is apparent on the levels of values (cf. Factor 1 orientation to employees and atmosphere in the company), norms of behaviour (Factor 7 - culture of ethic and friendship) and perception and behaviour in the organization (Factor 10 - behaviour oriented to employees and atmosphere in the company). The results indicate that it is considered important in the company to create a friendly atmosphere and good relations. Other crucial values include respect for employees, their support, information sharing, participation and encouragement of employees' innovativeness and creativity. The norms of behaviour present in the organization show a preponderance of politeness, honesty, openness, helpfulness towards fellow employees and mutual cooperation (cf. the medium level of Factor 7). This type of culture also exhibits a medium level of Factor 6, which means that such norms of behaviour are present in the company which express the responsibility towards the company, involvement and engagement for the benefit of the company, ability to act independently and flexibly, orientation to professionalism and self-development. There is a similar orientation apparent on the level of behaviour - managing people in the company means giving them independence and freedom, enabling them to come up with creative solutions, motivating them and creating conditions for their work. Employees are expected to be creative and individually responsible. Most employees know how they contribute towards meeting the corporate strategy; their shared aims and belief in success form the basis for the company's cohesion. Power is not asserted and the management style si not directive (cf. the low level of Factor 14). The strategic orientation seems to be characterized by an orientation to quality and customers. Quality and customers' satisfaction are, apart from employees' satisfaction, important criteria by which the management judges the success of the company (cf. Factor 10). Such a strategic orientation is also indicated by the medium level of Factor 2 on the level of values (orientation to quality of products and services, perfection, meeting deadlines, honesty towards customers and meeting their needs) and Factor 11 on the level of behaviour (the company's activities are oriented towards acquiring / strengthening its position in the market and defeating the competitors, which is reflected in the company's behaviour by fashioning its activities in order to ensure customer satisfaction and quality of service, as well as its willingness to take risks). The results also indicate that companies with this type of culture do not consider expansion and the defeat of one's competition as important (cf. Factor 3 on the level of values and Factor 13 on the level of behaviour) and that there is no internal competitiveness within the company (cf. Factor 9 on the level of values).

The culture identified by means of Cluster 4 is, to a certain extent, a counterpart of the culture characterized by Cluster 3 and the culture described in the interpretation of Cluster 1. It is strongly oriented to expansion and defeat of the competition, though in combination with a very low orientation to 
employees and their support. This is evidenced, as shown in Graph 1, by high levels of Factor 3 on the level of values (orientation to expansion), Factor 11 on the level of behaviour (orientation to the market and customers) and Factor 13 (orientation to the defeat of one's competitors). This means that companies with this type of culture consider it important to expand in the market, defeat one's competitors, react flexibly to new opportunities, as well as look for new possibilities and directions of their development. The activities are oriented to acquiring / strengthening one's position in the market and defeating one's competition which is perceived as an opponent. Emphasis is placed on flexibility, the company's active behaviour, openness towards signals from the external environment, performance and results. There is a willingness to take risks. By contrast, low levels are exhibited by factors oriented to employees, i.e. Factor 1 on the level of values and Factor 10 on the level of behaviour. This means that the company does not respect its employees, it is not considered important to create a friendly atmosphere and good relations, and the company does not encourage its employees and enable their further development. Employees are not expected to show initiative and creativity. Power is asserted and, as the high level of Factor 14 indicates, the directive style of management based on orders and control is present in the company. The external environment is perceived as unfriendly, confusing, unstable and highly competitive. The management judges the company's success according to external achivements. The source of cohesion is not the desire to achieve something but the attempt to survive in the market. The content of this culture is supplemented by interesting norms of behaviour present in companies with this culture: Factor 8 (culture of passivity and conformity) is very high, Factors 9 (culture of competitiveness and avidity) and 6 (culture of involvement and responsibility) are on a medium level, while Factor 7 (culture of ethic and friendship) is rather low. It is therefore clear that the company is not governed by norms of behaviour encouraging politeness and honesty towards fellow employees and customers, helpfulness and cooperation, nor by norms leading to self-development and increasing one's qualifications. On the contrary, there is a prevalence of norms of behaviour which encourage satisfaction with the status quo, conformity, following orders, insincerity and caution about one's statements. These partially combine with competitiveness and careerism inside the company and the employees' fight for money and positions. However, as mentioned above, a medium level is also exhibited by Factor 6, which includes norms encouraging responsibility and loyalty towards one's company, involvement for the company's benefit, professionalism and self-development. Incongruent as this result may appear at first sight, it is possible that there is in fact no discrepancy in it - involvement, loyalty and self-development may have an instrumental character, i.e. they may be connected with one's orientation to performance, results and efforts to secure money and career. 


\section{Discussion of results}

The premise that the typical contents of organizational culture characteristic of the Czech environment at present may differ from the contents identified in Western European countries calls for the comparison of the present research with the results of studies performed in other countries. However, such a comparison is highly problematic because of a large number of limiting factors: the selection of indicators of organizational culture (both as regards the level of analysis and the content domains with their specific manifestations), the choice of a procedure for constructing a typology and the selection of specific statistical methods.

The typology of organizational culture of Czech manufacturing companies presented in this paper is an empirical typology based on the application of exploratory procedure and arriving at a set of typical instances with a real existence in the Czech Republic. This procedure required the initial collection of data concerning this phenomenon, followed by the identification of empirically distinguishable groups and the interpretation of data. However, most other typologies published in the literature available seem to have been arrived at as a result of a different procedure: their authors start from the theoretical construction of types (i.e. a construction out of current knowledge about this phenomenon) and create a model which is operationalised and empirically tested. In this way, typologies are created as heuristic tools serving for the description and comparison of phenomena. Particular organizations are then subjected to an analysis in order to identify the degree to which a set of manifestations characteristic of particular types is present in such organizations. This eventually leads to the identification of the cultures of the individual companies.

The empirical typology presented in this study represents identical constellations of respondents' answers (ascertained by means of individual dimensions which are not mutually independent). They are thus the typical combinations of the degrees of occurrence of particular content components of organizational culture identified on the levels of values, norms of behaviour and selected strategic aspects of perceiving and behaving. The individual types represent typical and empirically differentiated profiles of answers provided by managers of Czech manufacturing companies rather than any pre-conceived sets of selected characteristics of the phenomenon under investigation. Moreover, the typology obtained as a result of the present research was identified only on a sample of manufacturing companies, while other authors offer more universal typologies. As a result, a comparison with previously published typologies would not be correct.

The only typology with which the empirical types of Czech manufacturing companies obtained in this research could, in a brief outline, be compared (taking into account the limits of such a comparison), is the typology by 
Cameron and Quinn (1999). As the selection of items in the Organizational behaviour questionnaire, used in the research, was largely based on content domains of organizational culture identified by Cameron and Quinn, the requirement of identical indicators of the content of organizational culture is more or less preserved. ${ }^{3}$ If the empirical types of organizational culture of Czech manufacturing companies, identified in the present research, are then compared with the typology based on the Competing values model published by Cameron and Quinn, it may be stated that type 3 is more or less identical with the clan culture and type 4 corresponds to the market culture. The following is typical for the clan culture: the organization emphasizes the long-term benefit of human resources development and attaches great importance to cohesion and morale, the organization is a very friendly place to work where people share a lot of themselves, the organization is held together by loyalty or tradition, commitment is high and the organization places a premium on teamwork, participation, and consensus (Cameron/Quinn 1999). These are the same features that are included in type 3 identified in Czech companies. The market culture is a result-oriented organizational culture, with long-term focus on competitive actions and achievement of measurable goals and targets. People are competitive and goaloriented, the leaders are hard drivers, producers, and competitors, they are tough and demanding. The glue that holds organization together is an emphasis on winning. Reputation and success are common concerns (Cameron /Quinn 1999). The same characteristics appear in type 3 identified in the Czech sample.

The research into Czech manufacturing companies did not identify the type which Cameron and Quinn refer to as the hierarchy culture. This type is characterized by an orientation to procedures and maintenance of a smoothrunning organization. In this culture, the management of employees is concerned with secure employment and predictability, success is defined in terms of dependable delivery, smooth scheduling, and low cost. Formal rules and policies hold the organization together (Cameron/Quinn 1999). Its focus on security makes it partly similar to type 1 identified in this study, but the latter does not include an orientation towards efficiency, which is so typical for the hierarchy culture. No parallel has been found with the adhocracy culture either; this being characterized by a dynamic, entrepreneurial-style environment inside the organization, where people stick their necks out and take risks, where the

3 Content components are understood to be those areas of perceiving, feeling, thinking and behaving of members of an organization in which the content of culture is manifested most and whose specific characteristics are crucial for the identification of the content of organizational culture (i.e. those that are crucial for delimiting the content of the culture of an organization). Cameron and Quinn's concept influenced only the selection of content components, i.e. indicators of organizational culture on the level of perceiving and behaving, but it did not affect the content of the respondents' replies (i.e. it only affected the selection of the items in the questionnaire but not the alternative answers). 
emphasis is on being on the leading edge and on growth and acquiring new resources, where individual initiative and freedom are encouraged and success means gaining unique and new products or services (Cameron/Quinn 1999). It thus seems that the focus on innovativeness, experimenting, and the related risk may not be considered as a typical form of strategic thinking and behaving of Czech manufacturing companies. The support of employees' innovativeness and creativity forms, however, an inseparable part of the Czech culture oriented towards employees (cf. the description of the content of type 3 ).

In this context, one is tempted to ask what determines the typical contents of organizational culture of Czech manufacturing companies idenfitied in the research: to what extent they are the consequences of the specific history (the socialist phase of development), to what extent they reflect the specific character of the Czech national culture, and to what extent they are determined by the fact that the researched sample consisted only of manufacturing companies.

A specific type of culture identified in Czech manufacturing companies is the culture oriented to certainty connected with passivity and conformity (see description of type 1), which is characterised by an unclear strategic orientation and a slight market-orientation. It is possible that this culture is present in those companies which failed to accommodate to the market environment and are passive and inflexible. This kind of behaviour could be connected with the fact that such thinking and behaviour is a consequence of previous history. This kind of culture could perhaps be functional in a non-market environment, but under market conditions, it is an obstacle to the companies' success. It is probable that the same tendencies could be found in the behaviour of some companies in other post-Communist countries. Unfortunately, no comparable research into organizational culture of manufacturing companies in other post-Communist countries could be located. This assumption thus cannot be verified and needs to be considered as hypothetical.

Such a "strategic indefiniteness" is characteristic not only for type 1 identified in the present research but also for type 2. In the latter case, it combines with the internal incongruity of the content of organizational culture on the level of values and behaviour (contrary values are held in the company, where activities with an incongruent content are likely to be implemented, while the management of such companies does not realize the incongruity of the content and does not pay attention to it). It may be assumed that this feature may be determined by an insufficient or bad strategic management and an insufficient emphasis on the strategic orientation of organizational culture. This may be indicative of the fact that strategic management in some manufacturing companies tends to be underestimated, the management of the companies does not possess sufficient knowledge and the strategic priorities do not find their reflection in the content of organizational culture. 
However, it needs to be pointed out that although the strategic indefiniteness and the internal inconguity of strategic aspects of organizational culture do, as the research has shown, exist in many Czech manufacturing companies, it cannot be assumed on the basis of the above comparison that a similar strategic indefiniteness does not exist in companies in Western countries. Because the typology by Cameron and Quinn is, as mentioned, a heuristic typology, i.e. it anticipates a certain strategic orientation for each type, the comparison is not, in this respect, entirely correct. Diagnostic tools based on the typology by Cameron and Quinn try to ascertain the extent to which individual content types (with certain strategic priorities characteristic for each individual type) are present in the organizational culture of particular companies. For instance, the study by Yeung, Brockbank and Ulrich (1991, after Cameron/Quinn 1999), carried out by means of Cameron and Quinn's OCAI questionnaire on the sample of 1064 companies, showed, however, that 22 per cent of companies had no dominant type of culture, in 6 per cent of the firms all the cultures were equally dominant and "surprisingly, no firms were dominated by the market quadrant" (Cameron/Quinn 1999: 139).

As regards the fact that the type of culture oriented to clear rules and procedures has not been identified in Czech manufacturing companies may be explained with respect of the effect (or partial effect) of the Czech national culture. Thus findings obtained on the basis of a comparison of the mutual perception of Czechs and Germans, based on the concept of cultural standards, have shown that one of the key standards and the typical feature of the Czech national culture is the tendency to improvise (Nový/Schroll-Machl et al. 1999). In the Czech environment, this is appreciated as a manifestation of flexibility and genuinity. However, this does not mean that Czech manufacturing companies lack rules, established procedures and an effort to achieve efficiency (cf. e.g. the content of type 3, for which focus on perfection and meeting of deadlines are characteristic). After all, the Czech culture is, according to studies carried our by means of Hofstede's methodology, a culture characterized by a high degree of avoidance of uncertainty, which leads to the formulation of rules (Prücha 2004). But formal rules and standard procedures do not represent, from the point of view of strategic aspects of the culture of Czech manufacturing companies, a key and typical content, i.e. something that Czech companies would consider as an aim, an important value, a priority or a measure of success.

The type of culture oriented to innovation and experimentation has not been identified either. This fact is, in our opinion, the result of the composition of the sample under investigation. This was made up of manufacturing companies with the highest proportion of engineering and metal-working companies. If the sample had been made up of companies active e.g. in the field of information and communication technologies, in turbulent markets or companies from the 
"brainpower" sectors, the results obtained in this research would most likely have been different.

\section{Conclusion}

The study presents the results of research whose aim has been, using an empirical construction of typology, to map the typical contents of strategic aspects of organizational culture of Czech manufacturing companies. The construction of the typology has been performed on the levels of organizational values, norms of behaviour and selected aspects of perceving and behaving.

The research has identified the following empirical types of organizational cultures of Czech manufacturing companies:

1. Culture oriented to security combined with passivity and conformity;

2. Culture without a clear-cut character as regards its content and strategy, with a light prevalence of orientation to employees, partially internally incongruent;

3. Culture strongly oriented to employees and friendly atmosphere in the organization combined with focus on quality and customers;

4. Culture oriented to expansion and defeat of competition combined with a negative perception of the external environment and "unhealthy" environment inside the organization.

The ascertained types represent a set of typical contents of organizational culture present in manufacturing companies in the Czech Republic. Czech managers can draw on this typology for information about the contents of culture currently present in the Czech context and for making comparisons with the content of their own company's culture. In this way, they will be able to learn more about the culture of their firms (because the knowledge of the description of the typical contents of culture ensures their perceptibility towards cultural manifestations in their companies), understand it, and, as a result, be able to reflect on how much the cultures of their companies are in harmony with the companies' goals and strategies.

The results of the research may, however, also provide inspiration for company managers in other post-Communist countries, where some similar tendencies in the contents of cultures of manufacturing companies may be anticipated. It would be desirable if comparative studies are carried out in several countries both post-Communist countries and those which did not experience this historical period. Such research studies could help to identify identical tendencies in the behaviour of companies in post-Communist countries and document the determining effects of the previous historical situation. 
The strength of the present study consists in the authors' attempt to characterize the content of organizational culture on several levels, namely on the levels of values, norms of behaviour and perceiving and behaviour in companies. Mainly the characterization of the norms of behaviour in connection with other contents of organizational culture provides interesting and important information about the culture of the researched companies. The present research, however, has been limited (apart from its methodological difficulty) by the size of the sample, which does not permit deeper analyses focusing on the effect of the branch, length of the company's existence, etc. Further research into this topic is therefore highly desirable.

\section{References}

Cameron, K. S./Quinn, R. E. (1999): Diagnosing and Changing Organizational Culture. Reading, Mass.: Addison-Wesley Publishing Company.

Deal, T. E./Kennedy, A. A. (1982): Corporate Cultures. Reading, Mass.: Addison-Wesley Publishing Company.

Denison, D. R. (1990): Corporate Culture and Organizational Effectiveness. New York: John Wiley \& Sons.

Drennan, D. (1992): Transforming Company Culture. London: McGraw-Hill Book Company.

Fernandez, J. E./Hogan, R. T. (2003): The character of organizations, in: The Journal of Business Strategy, 24, 1, $38-40$.

Goffee,R./ Jones, G. (1998): The Character of a Corporation. New York: Harper Business.

Hall, W. (1995): Managing Cultures: Making Strategic Relationships Work. Chichester: John Wiley \& Sons.

Handy, Ch. (1993): Understanding Organizations. Harmondsworth: Penguin Books Ltd.

Kotter, J. P./Heskett, J. L. (1992): Corporate Culture and Performance. New York: Maxwell Macmillan.

Marcoulides, G. A./ Heck, R. H. (1993): Organizational Culture and Performance: Proposing and Testing a Model, in: Organization Science, 4, 2, 209 - 225.

Martin, J. (1992): Cultures in Organizations. New York: Oxford University Press.

Lukášová, R. (2006): Organizační kultura českých výrobních firem: hodnoty a normy chování, in: Psychologie v ekonomické praxi, 41, 2-3, 131 - 139.

Lukášová, R. (2005): Organizational culture of Czech manufacturing companies, in: Management in organizations: systematic research, 36, $119-131$.

Lukášová, R. (2004): Strategic Aspects of Organizational Culture of Czech Companies, in: Journal of East-West Business, 10, 1, 93 - 104.

Lukášová, R./ Nový, I. et al. (2004): Organizační kultura. Praha: Grada Publishing.

Nový, I./Schroll-Machl, S. et al. (1999): Interkulturní komunikace v řízení a podnikání. Praha: Management Press. 
O'Reilly III, Ch. S./Chatmann,J./Caldwell, D. F. (1991): People and Organizational Culture: A Profile Comparison Approach to Assessing Person-Organization Fit, in: Academy of Management Journal, 34, 3, $487-516$.

Průcha, J. (2004): Interkulturní psychologie. Praha: Portál..

Sackmann, S. (1991): Uncovering Culture in Organizations, in: Journal of Applied Behavioral Science, 27, 3, $295-317$.

Sackmann, S. (2002): Unternehmenskultur: analysieren - entwickeln - verändern. Neuwied Kriftel: Luchterhand.

Schein, E. H. (1985): How Culture Forms, Develops, and Changes, in: Kilman, R. H./Saxton, M. J./Serpa, R.et al.: Gaining Control of the Corporate Culture, San Francisco: JosseyBass Publishers.

Trice, H. M./Beyer, J. M. (1992): The Cultures of Work Organizations. Englewood Cliffs: Prentice Hall.

Trompenaars, F. (1993): Riding the Waves of Culture: Understanding Cultural Diversity in Business. London: The Economist Books.

Wiley, J. W./Brooks, S. M. (2000): The High-Performance Organizational Climate, in: Ashkanasy, N. M./Wilderom, P. M./Peterson, M. F. (ed.): Handbook of Organizational Culture \& Climate, London: Sage Publications, $177-191$. 